\section{PROPOSTA DE ATIVIDADE LÚDICA EM UMA PERSPECTIVA PIAGETIANA: POSSIBILIDADES AVALIATIVAS E FORMATIVAS}

Proposal of playful activity from a Piagetian perspective: evaluative and formative possibilities

Propuesta de actividad lúdica en una perspectiva Piagetiana: posibilidades de evaluación y formativas

\begin{abstract}
Resumo
Os jogos têm acompanhado o ser humano no decorrer de sua evolução, sendo recentemente inserido no sistema educacional. Neste sentido, elaborou-se uma atividade lúdica (história em quadrinhos) avaliativa e formativa, construída a partir da epistemologia Piagetiana, com objetivo de avaliar se os conceitos da referida teoria trabalhados com os alunos de Pósgraduação em uma disciplina de Epistemologia Genética de Jean Piaget haviam sido assimilados, e também apresentar/ressaltar aos alunos a possibilidade de desenvolver jogos e/ou atividades lúdicas aliadas a teorias de ensino e aprendizagem. Por meio da pesquisaação, verificou-se que os alunos se apropriaram de boa parte dos conceitos trabalhados na disciplina, contudo, identificou algumas lacunas em relação a acomodação de alguns termos. Os resultados possibilitam inferir que o lúdico aliado a teorias de ensino e aprendizagem pode ser utilizado para ensinar conceitos Químicos, de forma a contribuir para a aprendizagem dos alunos.

Palavras-Chave: Lúdico; Teorias de ensino e aprendizagem; Epistemologia Genética; Química.
\end{abstract}

\begin{abstract}
The games have accompanied the human being in the course of its evolution, being recently inserted in the educational system. In this sense, an evaluative and formative play (comic book) activity was constructed, based on the Piagetian epistemology, with the objective of evaluating if the concepts of this theory worked with the students of Graduate studies in a discipline of Genetic Epistemology of Jean Piaget had been assimilated, and also to present/highlight to the students the possibility of developing games and/or play activities allied to teaching and learning theories. Through the action research, it was verified that the students appropriated much of the concepts worked in the discipline, however, identified some shortcomings in relation to the accommodation of some terms. The results make posible to infer that the playful allied to teaching and learning theories can be used to teach Chemical concepts, in order to contribute to the students' learning.
\end{abstract}

Keywords: Playful; Teaching and learning theories; Genetic Epistemology; Chemistry.

\section{Resumen.}

Los juegos han acompañado al ser humano en el transcurso de su evolución, siendo recientemente insertado en el sistema educativo. En este sentido, se elaboró una actividad lúdica (historietas) evaluadora y formativa, construida a partir de la epistemología Piagetiana, con el objetivo de evaluar si los conceptos de la referida teoría trabajados con los alumnos de Postgrado en una disciplina de Epistemología Genética Jean Piaget habían sido asimilados, y también presentar/resaltar a los alumnos la posibilidad de desarrollar juegos y/o actividades lúdicas aliadas a teorías de enseñanza y aprendizaje. Por medio de la investigación-acción, se verificó que los alumnos se apropiaron de buena parte de los conceptos trabajados en la disciplina, sin embargo, identificó algunas lagunas en relación al acomodamiento de algunos términos. Los resultados posibilitan inferir que el lúdico aliado a teorías de enseñanza y aprendizaje puede ser utilizado para enseñar conceptos Químicos, para contribuir al aprendizaje de los alumnos.

Palabras clave: Lúdico; Teorías de enseñanza y aprendizaje; Epistemología Genética; Química.

\section{AUTORES:}

\section{ADRIANO JOSÉ DE} OLIVEIRA

ORCID 0000-0001-8660-6983

${ }^{1}$ Universidade Federal de Goiás (UFG)

FELIPE AUGUSTO DE MELLO REZENDE ${ }^{2}$

ORCID 0000-0003-1390-3658

${ }^{2}$ Universidade Federal de Goiás (UFG)

THIAGO CARDOSO DE DEUS 3

ORCID 0000-0003-4763-9162

${ }^{3}$ Instituto Federal de Goiás (IFG)

VICTOR RICARDO FELIX FERREIRA ${ }^{4}$

ORCID 0000-0002-9062-9202

${ }^{4}$ Universidade Federal de Goiás (UFG)

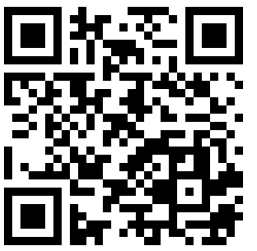

Para citar este artigo:

OLIVEIRA, A. J.; REZENDE, F. A. M.; DEUS, T. C.; FERREIRA, V. R. F. Proposta de atividade lúdica em uma perspectiva piagetiana: possibilidades avaliativas e formativas.

Revista

Eletrônica Ludus Scientiae, Foz do Iguaçu, v. 02, n. 01, p. 19-33, jan./jun., 2018. 


\section{INTRODUÇÃO}

Os jogos fazem parte da construção do ser social, pois acompanha o ser humano no decorrer de sua existência. Os primeiros indícios de utilização de jogos datam o período da Grécia e Roma antigas, cujos filósofos Aristóteles e Platão discutiam a importância de se aprender brincando. Neste período, as doceiras confeitavam guloseimas na forma de letras do alfabeto, com intuito de ensinar as crianças a ler, e os soldados utilizavam-se dos jogos para preparar estratégias de ataque e defesa, como forma de preparação para as batalhas (KISHIMOTO, 2011a).

O interesse pelo jogo decresce com o Cristianismo, que por meio da igreja Cristã tenta impor uma educação mais disciplinadora, pautada em princípios que distanciam o lúdico da vida das pessoas, pois os jogos eram levianamente associados a atividades delituosas como a prostituição e embriaguez. Com o passar dos anos, a igreja católica foi perdendo força e diferentes concepções de mundo culminaram em um novo período da história denominado Renascimento. Este período do século XVI foi extremamente importante para o renascimento do jogo, tendo grande contribuição de Ignácio de Loyola e Thomas Murner, que os utilizaram para ensinar dialética aos nobres (KISHIMOTO, 2011b).

As mudanças iniciadas pelos pensadores no período do Renascimento, se expandem no século XVII, resultando em estudos acerca do jogo, e o movimento que se iniciou na Grécia e Roma antigas, eclode no século XVIII, com a popularização dos jogos, que antes se restringiam aos nobres, passa a se tornar um elemento presente nas diferentes classes. Neste período, Froebel (2001) insere-o no âmbito pedagógico, desenvolvendo um sistema de educação infantil com a utilização de jogos, que segundo o pesquisador, deveria fazer parte de todos os estágios da vida do ser humano (KISHIMOTO, 2011b). Assim, Duflo (1999) considera o século XVIII como o século do jogo, definindo-o como o momento mais importante da história contemporânea dos jogos, período em que ele deixa de ser insignificante e passa a ser pensado como um elemento importante da antropologia.

Embora os relatos acerca da utilização de jogos e atividades lúdicas remetam a milhares de séculos, pouco caminhou-se acerca do lúdico como metodologia de ensino. A dificuldade em relação a compreensão do objeto de estudo se agrava ainda mais quando verificamos na literatura brasileira o significado do termo brinquedo, "objeto para as crianças brincarem; jogo de criança, brincadeira" (FERREIRA, 2011, p. 156). Os termos, jogo, brinquedo e brincadeira, são compreendidos como sinônimos, sendo que cada um apresenta um significado distinto, assim como o termo atividade lúdica, que muitas das vezes é compreendida como sinônimo do brincar.

De acordo com Soares (2013), atividade lúdica é uma ação que proporciona divertimento aos participantes, sem levar em consideração os objetos relacionados, podendo ou não ter regras, estando inserida nos diversos contextos linguísticos. Quando o indivíduo participa de uma atividade lúdica, ele se entrega de forma plena e integral à sua execução, Luckesi (1998) discute a característica da atividade lúdica e sua capacidade de envolver os participantes.

Enquanto estamos participando verdadeiramente de uma atividade lúdica, não há lugar, na nossa experiência, para qualquer outra coisa além dessa própria atividade. Não há divisão. Estamos inteiros, plenos, flexíveis, alegres, saudáveis (LUCKESI, 1998, p. 2).

Dentre as diversas atividades lúdicas, podemos citar Histórias em Quadrinhos, Paródias, Peças Teatrais, Caça Palavras, Quebra-Cabeça, brincadeiras, jogos, coleções, atividades que proporcionam diversão e envolvem os participantes.

As Histórias em Quadrinhos, também chamadas de HQs, de acordo com Ramos (2009), são uma maneira de apresentar/contar uma história por meio de uma série de desenhos, técnica herdada das primeiras civilizações, que normalmente faziam desenhos nas paredes das cavernas para contar como ocorriam suas experiências na caça e/ou vivencias cotidianas. De acordo com o autor, a HQ é 
uma forma de apresentação textual que prende bastante a atenção das pessoas, atingindo diferentes faixas etárias, de crianças a idosos.

As HQs podem ser utilizadas no sistema educacional, podendo ser inseridas na discussão e/ou apresentação de conceitos científicos. A ludicidade presente em suas imagens, são capazes de chamar a atenção dos alunos e despertar o interesse pela aprendizagem, além do fato de estar presente no cotidiano de boa parte da sociedade, seja por meio de gibis, mangas ou até mesmo tiras de jornais (CRUZ, 2015).

Assim como as atividades lúdicas, os jogos têm como principal característica a diversão, mas o que os diferenciam das atividades lúdicas são as regras, uma característica inerente aos jogos. De acordo com Soares (2013), atividade lúdica corresponde às ações que geram um mínimo de prazer e divertimento, estando diretamente relacionada aos jogos, sendo que diferentemente dos jogos, pode ou não haver existência de regras. Se houver existência de regras na ação, além de atividade lúdica, ela pode também ser classificada como jogo, no entanto, se não houver, considera-se a ação como uma atividade lúdica. Neste sentido, todo jogo necessariamente é uma atividade lúdica, por estar diretamente relacionado à diversão, no entanto, nem toda atividade lúdica pode ser considerada um jogo, devido às regras.

Além das regras, existem algumas características que dão significação ao termo jogo, e Kishimoto (2011a) aponta algumas a partir do trabalho desenvolvido por Brougère (1997). De acordo com a autora, o jogo é compreendido como produto de um sistema linguístico inserido em um contexto social, ou seja, o jogo depende da linguagem presente no convívio dos indivíduos, portanto, é construído a partir da imagem e dos sentidos que são atribuídos a ele em cada sociedade. Neste sentido, o jogo tende a variar de uma cultura para outra, pois um mesmo objeto pode ser visto como jogo para uma determinada cultura, e para outra ter um significado diferente.

A autora cita como exemplo, uma criança atirando arco e flecha em um animal, que para muitos é visto como um jogo de acertar o alvo, mas para comunidade indígena nada mais é que a preparação para a caça, fundamental para sua subsistência (KISHIMOTO, 2011a). A autora destaca que mesmo com essa variação linguística, é possível especificar sua modalidade, pelo fato dos jogos terem uma estrutura sequencial, ou seja, um conjunto de regras.

Para Soares (2013), os diferentes tipos de jogos desempenham um importante papel no sistema educacional, devido ao seu caráter Construtivista, capaz de envolver os indivíduos criando um cenário de participação e construção coletiva do conhecimento, cujos esquemas iniciais influenciarão nas aprendizagens futuras. Dentre os estudiosos Construtivistas, temos Jean Piaget, que discute o papel dos jogos na formação das crianças, ressaltando sua importância no desenvolvimento infantil.

O jogo na concepção Piagetiana, é compreendido como um fenômeno do pré-exercício, que serve como preparação para as atividades posteriores. Neste sentido, o jogo pode ser explicado pelo processo biológico pelo qual os órgãos se mantem em funcionamento. Ou seja, para desenvolver, os órgãos necessitam de alimento, e conforme o processo se intensifica, as necessidades também acentuam. Os jogos desempenham o mesmo papel, pois conforme as crianças se desenvolvem, os jogos se intensificam conforme sua capacidade de assimilação. Para explicar melhor o processo, Piaget cria três categorias de classificação dos jogos, que variam de acordo com os estágios propostos: jogos de exercício, jogos simbólicos e os jogos de regras. Contudo, importante ressaltar que Piaget considera não apenas as questões biológicas, mas também questões sociais, que assim como os estímulos biológicos devem ser levados em consideração na escolha dos conteúdos presentes nos jogos, pois este deve-se adequar tanto a idade das crianças, quanto ao contexto social que os mesmos estão inseridos (PIAGET, 1978). 
Os jogos de exercício são caracterizados simplesmente pelo prazer funcional, cujo indivíduo realiza-o por mero divertimento, sendo desprovido de necessidade e aprendizagem. Estes jogos são os primeiros a aparecerem nas crianças, não requerem necessidade de pensamento, pois as ações não modificam as estruturas cognitivas. Piaget (1978) cita o exemplo de uma criança brincando em uma banheira com água, ao bater as mãos na água de forma aleatória, o prazer proporcionado por aquela ação caracteriza do jogo funcional.

A segunda categoria descrita por Piaget (1978), dos jogos simbólicos, compreende as ações que implicam representações de objetos ausentes, no qual a criança associa suas brincadeiras a objetos ou fatos recorrentes em seu cotidiano. $\mathrm{O}$ simbolismo presente em tais jogos, consiste em atribuir vida e/ou função a objetos corriqueiros, como por exemplo, a criança utilizar um cabo de vassoura como sendo seu cavalo na brincadeira, o mesmo cabo de vassoura passa a servir como uma lança em outro momento. Para realização dos jogos simbólicos, é necessário que a criança tenha situações assimiladas em sua estrutura cognitiva, pois seus jogos consistirão nas representações dos fatos vivenciados que ocorrerão de acordo com seu imaginário e seus interesses. O simbolismo propicia a imitação, que embora não transforme a estrutura cognitiva, começa a desenvolver nas crianças o sentido da construção e colaboração, pois mesmo que a imitação seja predominante, cada indivíduo terá seu papel no jogo simbólico (PIAGET, 1978).

Os jogos de regras supõem necessariamente relações sociais e interindividuais entre os participantes. Nesta etapa a criança começa a compreender e se adaptar à vida em sociedade, sendo que as regras impostas pelos grupos ressaltam a existência de limites, que devem ser respeitados para o bom andamento das ações. A partir dos jogos de regras, os participantes conseguem assimilar informações nas suas estruturas cognitivas, e por meio das situações vivenciadas podem até mesmo acomodar determinados conceitos (PIAGET, 1978).

A proposta de ensino baseada na concepção Piagetiana, tem como referência uma escola ativa no que se refere às estratégias de ensino que instigam o cognitivo dos alunos. Nesta perspectiva de Piaget (1967), os discentes organizam suas atividades a partir de um objeto mais ou menos preciso (jogo ou atividade lúdica) construído pelo docente que exerce um papel de mediador do conhecimento. Piaget desenvolve a Epistemologia Genética, que consiste em atribuir um papel primordial à atividade do sujeito no processo de construção do seu próprio conhecimento (GOULART, 2000).

A partir da Epistemologia Genética, Piaget formula a Teoria da Equilibração para explicar os mecanismos do desenvolvimento intelectual, que se processam por meio das interações estabelecidas entre sujeito e objeto de conhecimento, e apresentam uma relação dialética entre assimilação e acomodação (PÁDUA, 2009). Embora sua teoria não tenha sido elaborada para fins educativos, seus conceitos podem ser perfeitamente adaptados ao sistema educacional. David Ausubel exemplifica bem a aproximação da teoria Piagetiana com a educação, ao incorporar diversas concepções de Piaget na proposição de sua teoria denominada Aprendizagem Significativa (MOREIRA, CABALLERO e RODRÍGUEZ, 1997).

Para Piaget, o indivíduo nasce com esquemas primordiais, que são as informações inerentes ao ser humano, presentes em sua gênese. No processo de desenvolvimento (maturação), a criança adquire informações através da relação com o meio (assimilação), sendo-as integradas às estruturas já existentes (esquemas). O processo pelo qual a criança adquire novas informações e liga-as aos seus esquemas anteriores, dando-os significação, é denominado acomodação, que normalmente culmina na aprendizagem. A teoria Piagetiana, consiste em constantes processos de assimilação que podem levar à acomodação, mas também podem levar o indivíduo ao desequilíbrio, quando as novas informações não se ancoram às existentes na estrutura cognitiva. Contudo, mesmo que ocorram desequilíbrios, o sistema buscará restabelecê-lo por meio de novas assimilações/acomodações (GOULART, 2000). 
Na Teoria da Equilibração, os níveis de assimilação, acomodação e adaptação, normalmente variam de acordo com a idade das crianças, pois segundo Piaget o desenvolvimento não acontece de forma linear, mas através de saltos e rupturas que se processam nos estágios de desenvolvimento (PÂDUA, 2009). Os estágios correspondem às quatro fases de desenvolvimento da criança: sensóriomotora, pré-operatória, operatório concreto e operatório formal. Assim, estes períodos são marcados pela motricidade, aparecimento da linguagem, pensamento concreto e por último o formal, no qual a criança realiza raciocínios hipotético-dedutivos, sendo perceptível situações de abstração.

Diante às fases mencionadas, Piaget formula três formas de equilibração: INTRA, INTER e TRANS, que normalmente variam de acordo com a idade, pois cada uma delas ressalta as condições de assimilação e equilibração, que podem levar o indivíduo a elaborar novos conceitos diante suas relações com o real (AGUIAR JR, 1999). A primeira forma de equilibração corresponde à fase INTRA, que decorre da interação entre os esquemas que o sujeito possui e os objetos a assimilar. Esta é uma das interações mais elementares, cujas mudanças conceituais, consistem em fases prévias que ainda não foram ligadas entre si, ou se ligaram de maneira insuficiente. Desta forma, na medida em que as novas informações são apresentadas, o sujeito encontra-se obrigação de assimila-las aos esquemas existentes. Os obstáculos encontrados neste tipo de equilibração, decorrem da dificuldade de coordenação entre os esquemas que culminam em equilibrações mais simples (AGUIAR JR., 1999).

A segunda equilibração é a INTER, e consiste em uma busca de equilíbrio entre os esquemas de assimilação que o sujeito possui, havendo uma relação de associação, no sentido de promover uma complexidade da informação, de forma a relacioná-la com outras em busca de acomodação do conceito (AGUIAR JR, 1999).

A terceira forma de equilibração é a TRANS, e consiste além da associação com outros esquemas, na hierarquização das informações, promovendo uma reflexão em nível formal, crítico. $\mathrm{O}$ conceito já acomodado agora pode ser usado e associado a outros, em esquemas que a princípio não apresentavam relação direta com o conceito, mas que fazem parte de um todo do intelecto (AGUIAR JR, 1999).

Diante às definições de jogos e atividades lúdicas apresentadas, bem como sua caracterização a partir da Teoria da Equilibração de Jean Piaget, buscamos desenvolver uma proposta de atividade lúdica avaliativa e formativa, construída a partir da epistemologia Piagetiana. A atividade lúdica foi elaborada para avaliar se os conceitos da referida teoria trabalhados com alunos de pós-graduação em uma disciplina de Epistemologia Genética de Jean Piaget haviam sido assimilados, e também apresentar/ressaltar a possibilidade de desenvolver jogos e/ou atividades lúdicas aliadas a teorias de ensino e aprendizagem, que de acordo com Rezende (2017) tendem a contribuir e facilitar a aprendizagem dos alunos.

A relevância da proposta justifica-se pelas pesquisas realizadas por Garcez (2014) e Rezende (2017), que verificaram a ausência de teorias de ensino e aprendizagem no construto dos jogos (sejam eles avaliativos ou educativos), além de ressaltarem o quanto tais aspectos podem contribuir para a aprendizagem dos discentes, bem como para as pesquisas relacionadas a utilização de jogos na educação.

\section{METODOLOGIA}

A pesquisa foi realizada na perspectiva da pesquisa-ação, que consiste em um método qualitativo bastante utilizado por pesquisadores que pretendem desenvolver trabalhos para melhoria ou até mesmo avaliação da sua própria prática, de forma que os resultados possam culminar em uma melhor aprendizagem dos alunos (TRIPP, 2005). Embora não se saiba ao certo quem criou o método, diversos pesquisadores apontam que a base da Pesquisa-Ação é atribuída ao trabalho de Dewey (1929), 
devido ao seu pensamento crítico e reflexivo sobre o processo educativo, e suas ideias de democracia e participação.

O termo Pesquisa-Ação aparece pela primeira vez em 1946, a partir dos trabalhos de Kurt Lewin, que a concebe como uma investigação que partia de fora, funcionalista, cuja prática era autoritária, além de não poder aplicar-se às pesquisas desenvolvidas pelo professor em sala de aula. No entanto, com o passar do tempo as concepções acerca do método foram se alterando de acordo com o contexto sociocultural vivenciado pelos pesquisadores. Até que na década de 8o, pesquisadores como Corey apud Escudero (1987), Elliot (1981) e também Kemmis (1984) redefinem-na, considerandoa como um método importante no sistema educacional, capaz de analisar e refletir sobre a prática docente, e consequentemente melhorar a qualidade do ensino (BARRIO, 2002, p. 239).

[...] A pesquisa-ação é o tipo de pesquisa levada a termo em situações escolares e é projetada para ajudar as pessoas que trabalham lá entender se você está agindo corretamente ou incorretamente (COREY apud ESCUDERO, 1987).

[...] é um estudo de uma situação social, a fim de melhorar a qualidade da ação dentro dele (ELLIOT, 1981).

[...] é uma forma de investigação introspectiva de todos os participantes no processo educativo, a fim de melhorar a racionalidade e justiça de suas práticas educativas, a compreensão dessas práticas e situações em que estas práticas ocorrem (KEMMIS, 1984).

De acordo com Barrio (2002), a pesquisa-ação é um método de investigação que se fundamenta em um processo sistemático orientado pelo conhecimento existente, tanto do pesquisador quanto dos sujeitos que se aplicam à pesquisa, cujo conhecimento origina da práxis cotidiana e permite conhecer e transformar os envolvidos no processo, por meio da sistematização das experiências. "Ou seja, $a$ Pesquisa-ação tem como objetivo fundamental melhorar o processo educativo, através de caminhos ou propostas que surgem e se introduzem na prática docente de forma cíclica” (BARRIO, 2002, p. 240).

A pesquisa-ação é descrita por Tripp (2005) como um processo cíclico de quatro etapas (Figura 1), sendo que inicialmente o pesquisador deve se inserir no ambiente de pesquisa com intuito de identificar determinado problema, para posteriormente planejar e implementar uma ação, seguido de uma avaliação da mesma, que possibilite verificar sua eficácia, permitindo a continuidade do ciclo em busca de melhorias da ação inicial.

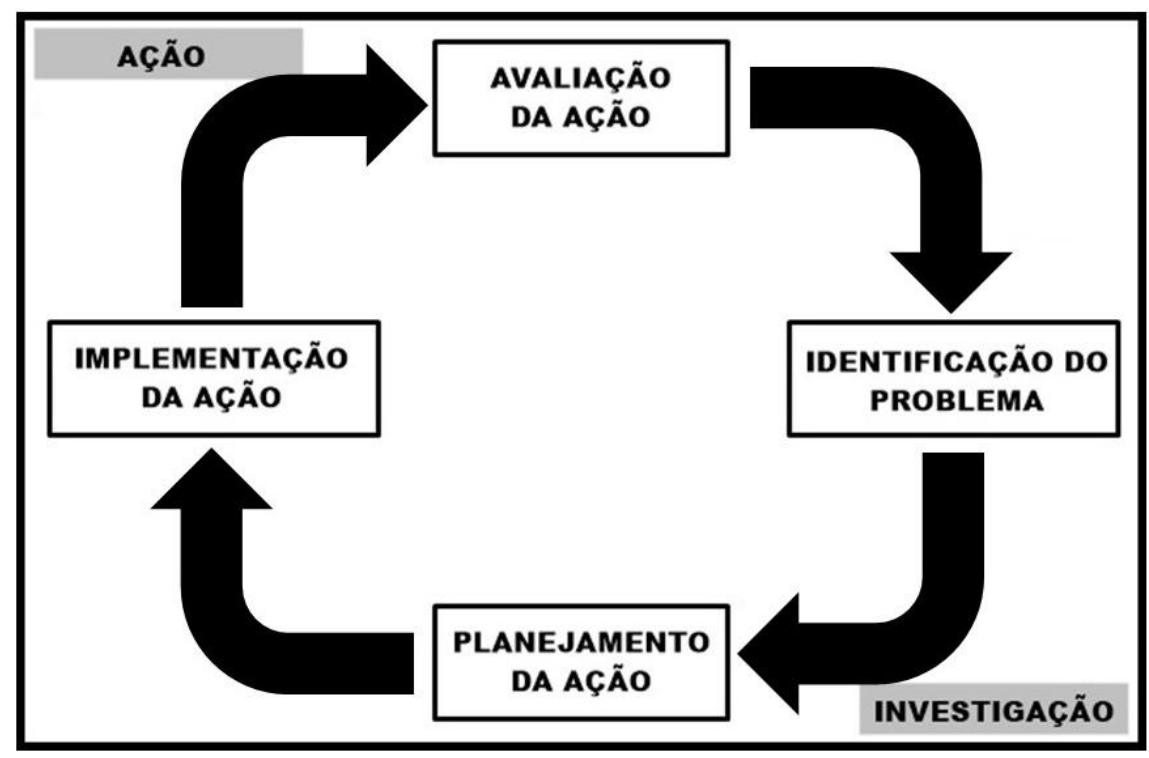

Figura 1: Representação do ciclo da Pesquisa-Ação utilizado na pesquisa. Adaptado de Tripp (2005). 
A maioria das pesquisas realizadas por meio da pesquisa-ação, iniciam-se com a identificação de um problema, que na pesquisa em questão, consiste na dificuldade encontrada pelos alunos da disciplina Epistemologia Genética de Jean Piaget em relação a compreensão de conceitos da teoria Piagetiana e sua aproximação com o ensino de Química. Percebendo tais dificuldades, procurou-se elaborar uma atividade lúdica (História em Quadrinhos) que pudesse além de avaliar a aprendizagem dos alunos em relação aos conceitos trabalhados na disciplina, elucidar uma proposta que aliasse a teoria Piagetiana ao lúdico, e fosse capaz de ensinar conceitos químicos aos alunos de forma divertida e pautada em uma teoria de ensino e aprendizagem.

A elaboração da História em Quadrinhos, levou em consideração os dois aspectos mencionados, conceitos da Epistemologia Genética e o ensino de Química em uma perspectiva lúdica. Para construção da proposta elaborou-se quatorze quadrinhos, que versam sobre uma situação cotidiana de sala de aula, no qual o professor de Química procura ensinar conceitos de ácido aos seus alunos, de forma que eles passassem por processos de desequilibração e assimilação, até conseguirem acomodar as informações repassadas.

A terceira etapa do ciclo, consiste na utilização da HQ como método de avaliação da aprendizagem dos alunos na disciplina de pós-graduação. Nesta etapa de aplicação da atividade, dividiu-se a turma em três grupos de quatro a cinco pessoas, sendo entregue a cada um os quadrinhos relacionados a história elaborada, solicitando aos mesmos que a organizassem de acordo com a lógica que lhes fizesse mais sentido, e posteriormente explicassem quais conceitos Piagetianos estariam presentes em cada quadrinho. A figura 2 elucida os quadrinhos elaborados, bem como a organização cronológica de acordo com a ideia inicial dos pesquisadores, lembrando que os alunos receberam quatorze folhas separadas (sem numeração), sendo que cada uma correspondia a um quadrinho, o que possibilitaria total liberdade na estruturação da HQ.

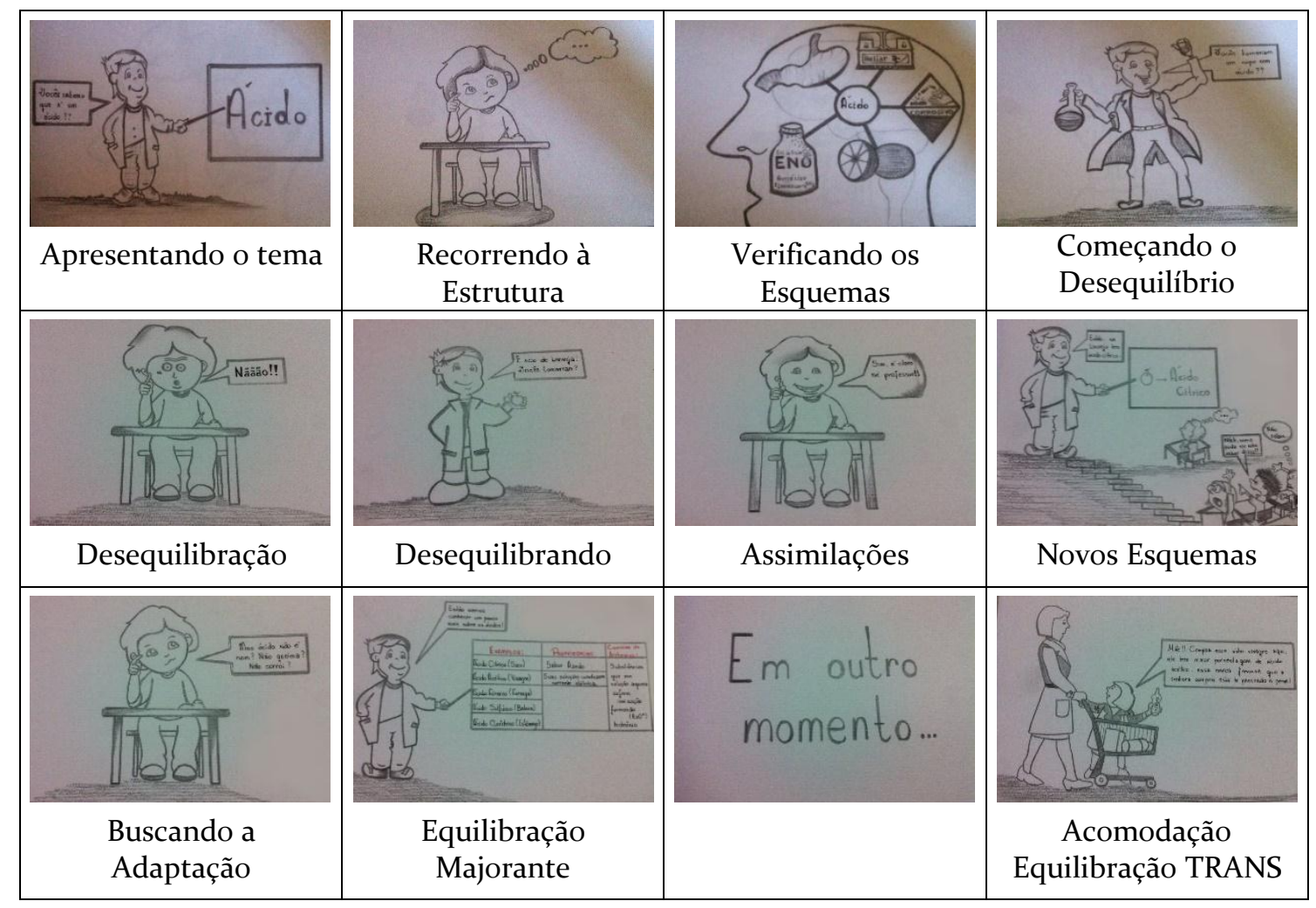




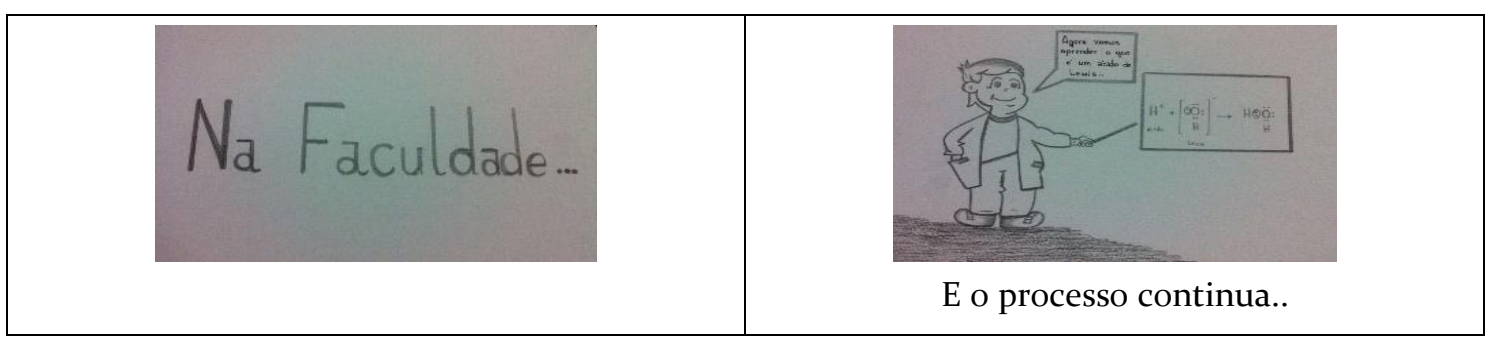

Figura 2: Representação dos quadrinhos da HQ (Autor).

No que diz respeito à história elaborada, iniciou-se os quadrinhos com uma pergunta que pudesse verificar os esquemas que os alunos possuíam acerca do conceito de ácido, pois é consenso que a palavra "ácido" apresenta uma polissemia de significados, que normalmente são associados a coisas perigosas, ruins. Desta forma, a partir dos esquemas primordiais dos alunos, iniciaram-se os processos de desequilibração, para desconstruir possíveis conceitos que foram assimilados de forma errônea (assimilação deformante). Assim, o professor desconstruiria a ideia do ácido ser associado apenas a coisas perigosas e ruins, mostrando aos alunos que o "ácido" está presente em nosso cotidiano, e que inclusive o ingerimos, possibilitando que eles assimilassem novas informações e construíssem novos esquemas, que gradativamente se complexariam, ao ponto dos alunos aprenderem o que vem a ser ácido e suas definições, bem como seriam capazes de raciocinar em um nível mais formal, utilizando e/ou associando tais aspectos com seu dia a dia.

Além da estruturação cronológica da HQ, solicitou-se aos grupos que discutissem entre si quais conceitos Piagetianos estavam presentes nos quadrinhos, para posteriormente apresentarem à turma, explicando os motivos que os levaram a montar a história na respectiva sequência.

Assim como descrito por Tripp (2005), uma das últimas etapas do ciclo consiste no monitoramento e avaliação da proposta inicial, que foram feitos por meio de métodos qualitativos de coleta de dados, tais como: questionário estruturado (Quadro 1), artigo de opinião e observação participante. Através do questionário e do texto escrito pelos jogadores, poderíamos analisar os resultados e ter um feedback dos alunos, que nos possibilitaria avaliar se os objetivos iniciais foram atingidos, bem como a necessidade de propor novas ações que pudessem melhorar a qualidade do ensino.

Quadro 1: Perguntas presentes no questionário (Autor).

\section{PERGUNTAS DO QUESTIONÁRIO}

Questão o1: Existiu algum critério na escolha da cronologia da história?

Questão 02: Houve dificuldades na montagem da história e/ou identificação de termos Piagetianos? Se sim, quais? Comente.

Questão 03: Há algum conceito que não apareceu e você gostaria de adicionar à história?

Questão o4: Como você avalia a atividade lúdica? Seria possível utilizá-la em uma aula de Química? Auxiliaria na aprendizagem dos alunos?

Questão 05: É possível trabalhar com o lúdico aliado a teorias de ensino e aprendizagem? O que isso impactaria na aprendizagem dos alunos?

Questão o6: O que você melhoraria na história para uma nova aplicação? 


\section{RESULTADOS E DISCUSSÃO}

A organização da HQ por parte dos alunos, evidenciou diferentes estratégias, pois cada um dos grupos (utilizaremos as denominações: Grupo I, Grupo II e Grupo III, para nos referirmos aos grupos) montou a história em uma cronologia diferente da apresentada na figura 2, levando em consideração tanto os conceitos químicos utilizados na história, quanto a Teoria da Equilibração de Jean Piaget.

O grupo I inicia a história com o quadrinho que faz a pergunta do que vem a ser um ácido, com intuito de identificar os esquemas que os alunos possuíam, ou seja, o conhecimento prévio deles. $\mathrm{Na}$ cronologia proposta pelo grupo (Figura 3), eles sugerem que entre o segundo e o terceiro quadrinho exista outro, que mostrasse o aluno verbalizando o que ele tem assimilado de ácido, para a partir de então iniciar o desequilíbrio. De acordo com o grupo, o desequilíbrio inicia-se no momento em que o professor pergunta se os alunos tomariam um copo de ácido, pois eles recorreriam aos seus esquemas que teriam assimilado que ácido seria algo perigoso, corrosivo (algo que os alunos consideraram devido ao "Nãããão" enfático que o quadrinho apresenta) e concluiriam que não tomariam.

Figura 3: Organização da HQ pelo Grupo I (Autor).

\begin{tabular}{|c|c|c|c|c|}
\hline $\begin{array}{c}\text { Identificação dos } \\
\text { Esquemas dos alunos }\end{array}$ & $\begin{array}{c}\text { Verificação dos } \\
\text { Esquemas }\end{array}$ & Início do & Recorrendo aos \\
Esquemas
\end{tabular}

No quinto quadrinho o professor retoma o processo de desequilibração, ao questionar os alunos se eles tomariam suco de laranja, sendo que eles recorreriam às suas estruturas cognitivas e responderiam que "Sim". Desta forma, o professor continua fazendo questionamentos, promovendo 
novas desequilibrações, que são decorrentes da associação dos esquemas que os alunos possuem de ácido com os esquemas relacionados à laranja, que como identificado anteriormente não apresentam ligação. A desequilibração é melhor evidenciada no oitavo quadrinho, quando o aluno se pergunta: "Mas ácido não é ruim? Não queima? Não corrói? Ou seja, o aluno faz a associação do conceito de ácido que possivelmente havia em sua estrutura cognitiva, com os novos repassados pelo professor, e percebe que há uma incongruência em relação às informações.

Após as desequilibrações, o professor inicia com os conceitos de ácido, favorecendo a construção de novos esquemas, que se processam até que os alunos sejam capazes de acomodar os conceitos de ácido trabalhados até então, que culminaria na equilibração majorante. O ponto final da história de acordo com o grupo, é o momento que o aluno está no supermercado com sua mãe e intervém na compra de vinagre, utilizando seus conhecimentos de ácido adquiridos em sala de aula, que culminaria na Equilibração TRANS. Na faculdade (último quadrinho) os alunos utilizariam tais conceitos, sem muitas dificuldades.

Embora o grupo não tenha estruturado a história na mesma cronologia proposta pelos autores da HQ, percebeu-se que ela não ficou sem sentido, e que os alunos conseguiram identificar os principais conceitos Piagetianos presentes nos quadrinhos, o que nos leva a inferir que os eles acomodaram os conceitos trabalhados na disciplina de Epistemologia Genética. A observação das discussões realizadas pelos membros do grupo, nos permitiu verificar que a HQ exemplificou bem os momentos de uma aula de Química, além de possibilitar a identificação de diversos conceitos presentes na Teoria da Equilibração, pois de acordo com os alunos o enredo da história além de aliar o lúdico à teoria de ensino e aprendizagem, aproxima os conceitos químicos do cotidiano dos discentes.

Os alunos mencionaram que utilizaram inicialmente apenas o conhecimento Químico para organizar a história (provavelmente essa estratégia justifica-se pela formação dos alunos, pois a maioria dos membros do grupo eram Químicos), e após a montagem da HQ, procuraram identificar nos quadrinhos os conceitos relacionados à teoria Piagetiana. De acordo com o grupo, a atividade poderia também ser aplicada na disciplina como um método de ensino, pois a forma com que a atividade foi construída (aliando lúdico, Química e Epistemologia Genética) facilitaria a compreensão (acomodação) de alguns conceitos Piagetianos.

O grupo II inicia a história também com o quadrinho que faz a pergunta do que vem a ser um ácido, e posteriormente trazem o quadrinho que apresenta uma nova pergunta, se os alunos tomariam um copo de ácido (Figura 4, próxima página). Os questionamentos iniciais realizados pelo professor, de acordo com o grupo, são importantes para que o docente conheça o que os alunos têm assimilado em sua estrutura cognitiva, pois para responder às perguntas seria necessário que os discentes recorressem ao seu conhecimento prévio sobre o assunto, mesmo que ele fosse proveniente do senso comum.

Ao recorrer às estruturas cognitivas, os alunos responderiam às perguntas com uma certa ênfase: "Nãããão!!", que deixa subentendido que eles possuem uma concepção negativa do que vem a ser ácido, associando-a ao perigo, à coisas ruins. Nos quadrinhos posteriores os alunos consideram novamente que o docente faz a pergunta: "E suco de laranja? Vocês tomariam?", para verificar os esquemas que os alunos possuem sobre ácidos, que respondem a partir das suas estruturas existentes. De acordo com o grupo, a desequilibração começa quando o professor explica que na laranja tem ácido cítrico, ou seja, eles ingeriam ácido sem ter conhecimento, processo que causa reflexão por parte dos alunos, pois até então ácido era associado a coisas ruins. 
Figura 4: Organização da HQ pelo Grupo 2 (Autor).

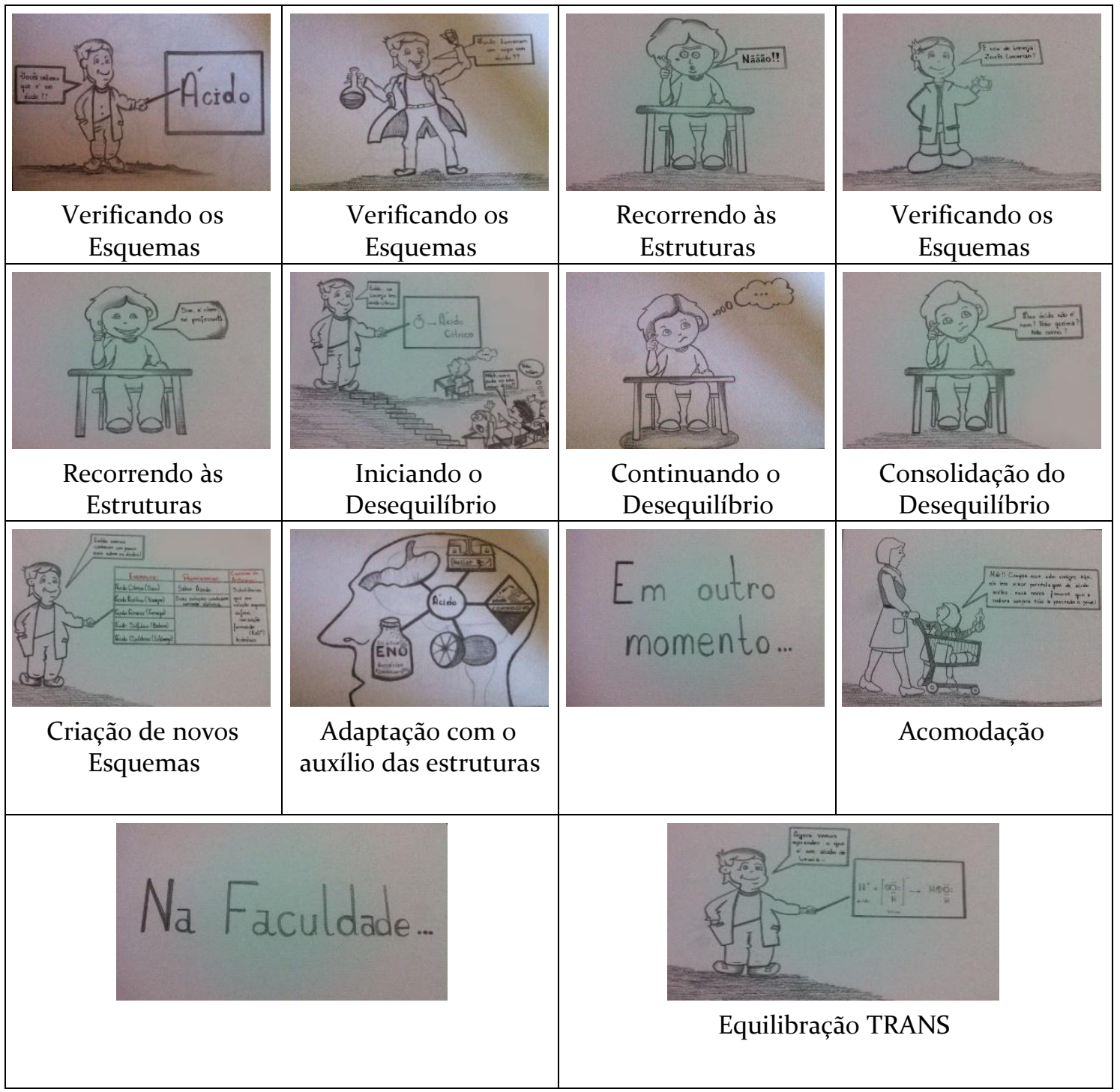

O momento em que o professor explica o que vem a ser ácido, suas propriedades e conceitos, é nomeado pelo grupo como criação de novos esquemas, pois estas informações não eram de conhecimento dos alunos, e ao serem apresentadas pelo docente são adaptadas em sua estrutura cognitiva com o auxílio das informações preexistentes, possibilitando relacionar o conceito de ácido à diversos aspectos: bateria de carro, antiácido, limão, estômago, corrosão. De acordo com o grupo, os alunos acomodam o conceito de ácido no momento em que eles conseguem diferenciar a qualidade de um vinagre em detrimento de outros, devido à quantidade de ácido acético. A história se encerra com o quadrinho do aluno na faculdade, momento em que ocorre a Equilibração TRANS, pois o aluno consegue raciocinar em um nível formal, realizando abstrações.

Analisando a cronologia apresentada pelo grupo II, percebemos que os discentes estruturaram a história em uma sequência diferente, explorando principalmente os conceitos mais comuns presentes na teoria Piagetiana: desequilibração, esquemas e estruturas cognitivas. O grupo utilizou os conceitos Piagetianos como estratégia para montar a história, de forma que os conceitos Químicos pudessem se "encaixar" em uma sequência lógica de equilibração em Piaget. A estratégia adotada pelos discentes, pode estar relacionada com a formação dos membros do grupo, pois como se trata de uma disciplina de pós-graduação, haviam alunos de diversas áreas de conhecimento, e o grupo em questão contava com apenas um Químico, os demais tinham como formação inicial Biologia ou Matemática, 
fator que dificultou a compreensão dos conceitos Químicos, mas não comprometeu os resultados, pois os alunos demonstraram conhecimento acerca da Teoria da Equilibração.

O grupo III inicia a história com uma pergunta: "Vocês tomariam um copo de ácido?", com intuito de promover uma desequilibração. Para responder à pergunta, os alunos teriam que recorrer às suas estruturas cognitivas, ou seja, o que eles teriam assimilado até então do que vem a ser ácido (Figura 5, próxima página). Em seguida, o professor faz mais uma pergunta, para verificar os esquemas que os alunos possuiam de laranja, e posteriormente fornecer informações que pudessem culminar em novos esquemas.

Quando o professor fala que na laranja tem ácido cítrico, os alunos assimilam esta nova informação (no quinto quadrinho, percebemos que alguns alunos assimilam, acomodam e outros são desequilibrados), pois até então eles associavam o conceito de ácido a algo ruim, que queimasse. De acordo com o grupo, além de assimilarem os alunos acomodam estas informações, pois há mudança do esquema que tem o conceito de ácido, que permite aos discentes relacionar o conceito de ácido com o da laranja.

Ao voltarmos aos quadrinhos, percebemos que os alunos buscam acomodar tal conceito, ao questionarem acerca das propriedades dos ácidos: “Mas ácido não é ruim? Não queima? Não corroi?", no entanto, não podemos considerar que o aluno acomodou tal conceito, pois não há um quadrinho que comprove tal afirmação. Neste sentido, consideramos que o grupo foi além das cenas dos quadrinhos, mas não consideramos como um erro, pois explicaram corretamente o que viria a ser a acomodação do conceito de ácido.

O professor volta a desequilibrar os alunos com a pergunta do que vem a ser um ácido, que possibilita também a verificação dos esquemas, no qual o professor identifica que houve assimilação e acomodação das informações repassadas anteriormente, pois ao pensarem sobre a pergunta, os alunos relacionam diversos esquemas ao esquema ácido, tais como: laranja, estômago, bateria de carro, antiácido, corrosão. Neste momento podemos considerar que de fato houve acomodação do conceito "ácido", pois o quadrinho com a imagem de um cérebro associando termos como: antiácido, estômago, laranja/limão, corrosão e bateria de carro à palavra ácido, garante tal afirmação.

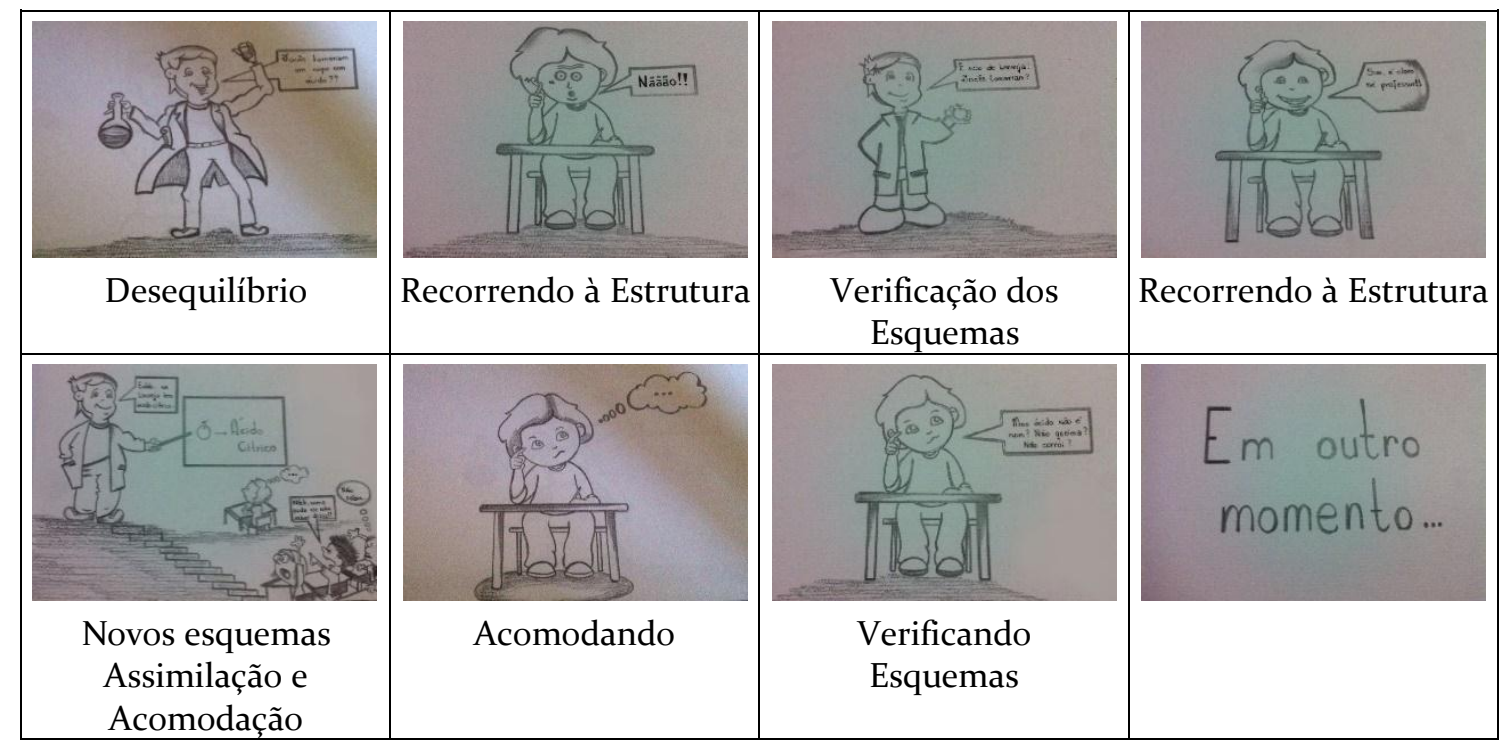




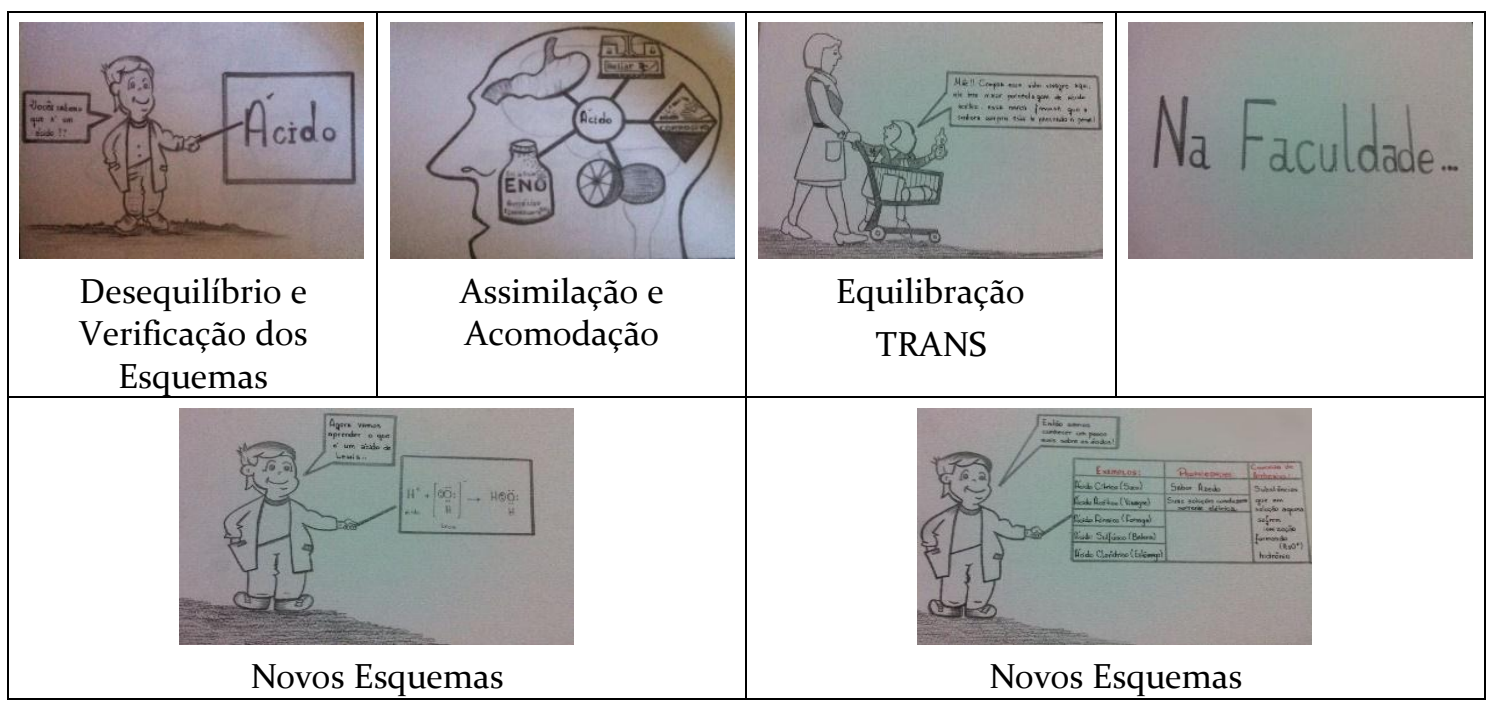

Figura 5: Organização da HQ pelo Grupo 3 (Autor).

A Equilibração TRANS ocorreria no momento em que o aluno vai ao supermercado com sua mãe, e utiliza os conceitos de ácido aprendidos em sala de aula para auxiliar na compra de um vinagre, ou seja, momento em que o discente consegue associar as partes com o todo. Para encerrar a história, o grupo considera que os quadrinhos que trazem explicação de ácido utilizando os conceitos de Arrhenius e Lewis, referem-se à construção de novos esquemas, que se processariam na faculdade.

A história proposta pelo grupo, diferiu-se das demais, mas os conceitos Piagetianos foram bem explorados, pois diferentemente dos dois grupos anteriores, os discentes utilizaram os diversos conceitos no decorrer da estruturação da HQ, e não apenas em um único quadrinho. Desta forma, consideramos que os discentes além de assimilarem os termos dentro da Teoria da Equilibração, também os acomodaram, pois conseguiram identificá-los no decorrer da história, e relacioná-los com o ensino de Química.

Analisando a estruturação das HQs e a explicação dos alunos em relação a sua montagem, percebeu-se que a atividade lúdica se mostrou uma importante ferramenta de avaliação da aprendizagem, pois permitiu-nos identificar que a maioria dos alunos acomodaram os conceitos trabalhados na disciplina de Epistemologia Genética, sendo perceptível também uma certa dificuldade de diferenciação e/ou identificação dos tipos de equilibração, pois foram pouco explorados na organização da HQ.

Os conceitos mais explorados por parte dos alunos, foram: desequilibração, esquemas e estrutura cognitiva, o que nos possibilita inferir que tais conceitos foram bem acomodados na estrutura cognitiva dos discentes, enquanto os demais, provavelmente não foram muito bem acomodados. Dentre os termos pouco utilizados e/ou não utilizados, destacamos a "adaptação", que foi explicitada por apenas um dos grupos, e por ser um conceito não muito simples de se compreender, provavelmente foi apenas assimilado (não acomodado) pela maioria dos discentes. Neste sentido, nas disciplinas posteriores, este conceito merece um(a) destaque/atenção maior por parte do professor.

De acordo com os alunos, os principais conceitos foram explorados na construção da HQ, não sendo necessário inserção de outros termos. Os discentes consideram que a atividade lúdica exerceu um papel avaliativo e também formativo, pois exemplificou bem o ensino de Ciências em uma perspectiva Piagetiana, podendo inclusive ser aplicada à alunos de Ensino Médio, pois a utilização do lúdico aliado à teoria Piagetiana, aproxima os conteúdos de Química com o cotidiano dos alunos, levando em consideração o conhecimento prévio dos discentes, assim, a aprendizagem seria favorecida principalmente por convergir em um ensino contextualizado e lúdico. 


\section{CONCLUSÃO}

Diante os resultados obtidos, concluímos que a atividade lúdica proposta mostrou-se uma importante e eficiente ferramenta de avaliação da aprendizagem, que nos possibilitou identificar a dificuldade de acomodação por parte dos alunos em relação a conceitos relacionados à adaptação e aos tipos de equilibração. Neste sentido, ressaltamos a necessidade de enfatizar e discutir mais estes conceitos nas disciplinas que serão ofertadas posteriormente.

O feedback obtido, evidenciou que os discentes gostaram da proposta e perceberam que o lúdico aliado a teorias de ensino e aprendizagem tende a contribuir para a aprendizagem dos alunos, pois na atividade desenvolvida, eles perceberam que a elaboração de uma proposta de ensino em um viés lúdico, aliado à Teoria da Equilibração aproxima o ensino de Química com o cotidiano dos alunos, pois o ensino parte do contexto no qual eles estão inseridos, o que favorece a aprendizagem.

Desta forma, concluímos que o lúdico aliado à epistemologia Piagetiana pode ser utilizado tanto como método avaliativo, quanto formativo, visto que os alunos da disciplina de pós-graduação ressaltaram que a atividade poderia ser aplicada no decorrer da disciplina como método de ensino. Assim, pretendemos desenvolver um novo ciclo da pesquisa-ação, no entanto, aplicando a HQ em uma turma de Ensino Médio, para analisarmos se a atividade lúdica aliada a uma teoria de ensino e aprendizagem favorece a aprendizagem de conceitos Químicos por parte dos alunos.

\section{REFERÊNCIAS}

AGUIAR JR., O. As três formas da Equilibração: Análise do material didático de um curso de eletricidade básica. Caderno Catarinense de Ensino de Física, v. 16, n. 1, p. 72-91, 1999.

BARRIO, J. B. M. El Planetário - un recurso didáctico para la enseñanza de la Astronomía. 2002. 338 f. Tese (Doutorado). Universidad de Valladolid. Programa de Doctorado en Didáctica de las Ciencias, Valladolid, 2002. BROUGÈRE, G. Jogo e Educação. 1. ed. Porto Alegre: ARTMED, 1997. 224 p.

CRUZ, T. M. G. S. Enquanto Isso na Sala de Justiça...História em Quadrinhos no Ensino de Química. 2015. 123 f. Dissertação (Mestrado). Universidade Federal de Goiás, UFG. Programa de Pós-Graduação em Educação em Ciências e Matemática, Goiânia, 2015.

DEWEY, J. The quest for certainty: a study of the relation of knowledge and action. New York: Minton, Balch \& Company, 1929.

DUFLO, C. O jogo: de Pascal a Schiller. Porto Alegre: Artes Médicas Sul, 1999. 85 p.

ELLIOT, J. Action Research: A frame work for self-evaluation in schools. Cambridge: CIE, 1981.

ESCUDERO, J. M. La investigación-acción en el panorama actual de la investigación educativa: algunas tendencias. Revista de Innovación e Investigación Educativa, p. 5-39, 1987.

FERREIRA, A. B. H. Aurélio Júnior: dicionário escolar da língua portuguesa. 2. ed. Curitiba: Positivo, 2011. $992 \mathrm{p}$.

FROEBEL. F. A. A Educação do homem. Tradução de Maria Helena Câmara Bastos. Passo Fundo: UPF, 2001. $120 \mathrm{p}$.

GARCEZ, E. S. C. O Lúdico em Ensino de Química: um estudo estado da arte. 2014. 142 f. Dissertação (Mestrado). Universidade Federal de Goiás, UFG. Programa de Pós-Graduação em Educação em Ciências e Matemática, Goiânia, 2014.

GOULART, I. B. Piaget: Experiências Básicas para Utilização pelo Professor. 17. ed. Petrópolis: Editora Vozes, 2000.

KEMMIS, S. A point by point guide to action-research. Victoria: Dea Kin University, 1984.

KISHIMOTO, T. M. (Org). Jogo, brinquedo, brincadeira e a educação. 14. ed. São Paulo: Editora Cortez, $2011 a$. $207 \mathrm{p}$.

KISHIMOTO, T. M. O brincar e suas teorias. São Paulo: Editora Cengage Learning, 2011b. 172 p. 
LUCKESI, C. C. Desenvolvimento dos estados de consciência e ludicidade. Cadernos de Pesquisa. Núcleo de Filosofia e História da Educação-UFBA, p. 9-25, 1998.

MOREIRA, M. A.; CABALLERO, M. C.; RODRÍGUEZ, M. L. Aprendizagem Significativa: um conceito subjacente. Actas del Encuentro Internacional sobre el Aprendizaje Significativo, Burgos: España, p. 19-44, 1997.

PÁDUA, G. L. D. A epistemologia Genética de Jean Piaget. Revista FACEVV, n. 2, p. 22-35, 2009.

PIAGET, J. A formação do símbolo na criança: imitação, jogo e sonho, imagem e representação. 3. ed. Rio de Janeiro: Zahar Editores, 1978. 370 p.

PIAGET, J. O raciocínio na criança. 2. ed. Rio de Janeiro: Record, 1967. 234 p.

RAMOS, P. História em quadrinhos: gênero ou hipergênero? Estudos Linguísticos, São Paulo, v. 38, n. 3, p. 355-367, 2009.

REZENDE, F. A. M. Jogos no Ensino de Química: um estudo sobre a presença/ausência de teorias de ensino e aprendizagem à luz do V Epistemológico de Gowin. 2017. $111 \mathrm{f}$. Dissertação (Mestrado). Universidade Federal de Goiás, UFG. Programa de Pós-Graduação em Educação em Ciências e Matemática, Goiânia, 2017.

SOARES, M. H. F. B. Jogos e atividades lúdicas no ensino de química: teorias, métodos e aplicações. Goiânia: Kelpes. 2013. 196 p.

TRIPP, D. Pesquisa-ação: uma introdução metodológica. Educação e Pesquisa, São Paulo, v. 31, n. 3, p. 443$466,2005$.

Felipe Augusto de Mello Rezende: Licenciado em Química pelo Instituto Federal de Educação Ciência e Tecnologia Goiano - Campus Urutaí, GO, Brasil (2011-2014). Mestre em Educação em Ciências e Matemática pela Universidade Federal de Goiás: Goiânia, GO, Brasil, 2015-2017. Possui experiência na área de Química, com ênfase em Ensino de Química. Trabalha com Jogos e Atividades Lúdicas no Ensino de Química.

E-mail: felipemelloquimica@hotmail.com

Thiago Cardoso de Deus: Licenciado em Química pela Universidade Federal de Goiás: Goiânia, GO, Brasil. 2000-2004. Mestre em Química pela Universidade Federal de Goiás: Goiânia, GO, Brasil, 2005-2008. Doutorando em Química pela Universidade Federal de Goiás: Goiânia, GO, Brasil. Possui experiência na área de Química, com ênfase em Educação em Química, atuando principalmente nas seguintes áreas: jogos e atividades lúdicas aplicadas ao ensino de Química, Inclusão Digital de professores, formação de professores e Avaliação da Aprendizagem. Atualmente é professor efetivo do Instituto Federal de Educação, Ciência e Tecnologia de Goiás - Campus Anápolis.

E-mail: thiagocdeus@yahoo.com.br

Adriano José de Oliveira: Licenciado em Química pela Universidade Federal de Goiás: Goiânia, GO, Brasil. 2001-2005. Mestre em Educação em Química pela Universidade Federal de Goiás: Goiânia, GO, Brasil, 20072009. Doutorando em Educação em Química pela Universidade Federal de Goiás: Goiânia, GO, Brasil. 20162019. Atualmente é professor de Química da rede Estadual de Ensino de Goiás. Possui experiência na área de Química, com ênfase no Ensino de Química. Trabalha com Jogos e Atividades Lúdicas, e Experimentação no Ensino de Ciências.

E-mail: adrianojoliveirazo10@gmail.com

Victor Ricardo Felix Ferreira: Licenciado em Química pela Universidade Federal de Goiás, Campus Samambaia: Goiânia, GO, Brasil, 2010-2014. Mestre em Química pela Universidade Federal de Goiás: Goiânia, GO, 2014-2016. Possui experiência na área de Química, com ênfase em Ensino de Química. Trabalha com Jogos e Atividades Lúdicas no Ensino de Química e Educação não-formal. Atualmente é professor do nível médio e superior da rede particular de ensino.

E-mail:vrfelixf@gmail.com 